\title{
XVI. Reflections on volcanos
}

\section{Gay-Lussac}

To cite this article: M. Gay-Lussac (1823) XVI. Reflections on volcanos, Philosophical Magazine Series 1, 62:304, 81-89, DOI: 10.1080/14786442308644383

To link to this article: http://dx.doi.org/10.1080/14786442308644383

$$
\text { 曲 Published online: } 23 \text { Jul } 2009 .
$$

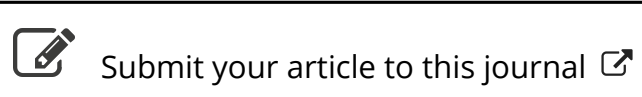

\footnotetext{
Џll Article views: 2
}

Q View related articles $\asymp$ 


\title{
PHILOSOPHICAL MAGAZINE AND JOURNAL.
}

\author{
31 st $A U G U S T 1823$.
}

XVI. Reflections on Volcanos. By M. Gay-Lussac. Read before the Royal Academy of Sciences at Paris, May 19, 1823 *.

BEFORE I offer to the public the following observations on volcanos, a subject which has so long presented a wide field for hypothesis and conjecture, I ought to premise that I am not in possession of all the knowledge necessary for its full discussion, and that I shall only take a brief and partial view of it, confining myself to certain questions upon which chemistry may throw some light, and which do not absolutely demand an acquaintance with geology. The subject is however one of considerable difficulty, and one which gives me a claim on the indulgence of my readers.

'Two hypotheses may be formed as to the cause which produces volcanic phænomena. According to one of these, the earth remains in a state of incandescence at a certain depth below the surface (a supposition strongly favoured by the observations which have been recently made on the progressive increase of temperature in mines); and this heat is the chief agent in volcanic phænomena. According to the second hypothesis, the principal cause of these phænomena is a very strong and as yet unneutralized affinity existing between certain substances, and capable of being called into action by fortuitous contact, producing a degree of heat sufficient to fuse the lavas and to raise them to the surface of the earth by means of the pressure of elastic fluids.

According to either of these hypotheses, it is sbsolutely necessary that the volcanic furnaces should be fed by substances originally foreign to them, and which have been some how or other introduced into them.

In fact, at those remote epochs which witnessed the great catastrophes of our globe,-epochs at which the temperature of the earth must have been higher than it now is, the melted substances which it contained consequently more liquid, the resistance of its surface less, and the pressure exercised by elastic fluids greater, -all that could be produced was pro-

* Ann. de Chimie et de Phys. tom. xxii. p. 415.

Vol. 62. No. 304. Aug. 1823. 
duced; an equilibrium must have established itself; the agitated mass must have subsided into a state of repose which could no longer be troubled by intestine causes, and which can only now be disturbed by fresh contact between bodies accidentally brought together, and which were, perhaps, only added to the mass of the globe subsequently to the solidification of its surface.

Now the possibility of contact between bodies in the interior of the earth, the ascent of lava to a considerable height above its surface, ejections by explosion, and earthquakes, necessarily imply that those extraneous substances which penetrate into volcanic furnaces must be elastic fluids, or rather liquids capable of producing elastic fluids, either by means of heat which converts them into vapour, or by affinity which sets at liberty some gaseous elements. According to analogy, the only two substances capable of penetrating into the rolcanic furnaces in volumes sufficiently large to feed them, are air, and water, or the two together. Many geologists have assigned to the air an important ofice in rolcanos; its oxygen, according to them, sustains their combustion: but a very simple observation will suffice to overthrow this opinion entirely.

How, indeed, is it possible for the air to penetrate into the volcanic furnaces when there exists a pressure acting from within towards the exterior, capable of raising liquid lava, a body three times as heary as water, to the height of more than 1000 mitres, as at Vesuvius, or even of more than 3000 , as is the case in a great number of volcanos? A pressure of 1000 metres of lava, equivalent to a pressure of 3000 metres of water, or to that of about three hundred atmospheres, necessarily excludes the introduction of any air whatever into volcanos; and as this pressure subsists for a long series of yenrs, during which the volcanic phanomena continue in the utmost activity, it follows that the air can have no share whesever in their production.

It is moreover evident, that if the air had a free commmication with the volcanic fumaces, the ascent of lava, and earthquakes, would be impossible.

If the air cannot be the cause of volcanic phanomena, it is probable, on the contrary, that water is a very important agent in them.

It can hardly be doubted that water does penetrate into volcanic furnaces. A great eruption is invariably followed by the escape of an enormous quantity of aqueous vapour, which, being condensed by the cold which prevails above the summits of volcanos, talls again in abundant rains accompanied by terrific thunder, as was the case at the famous eruption of Vesuvius in 1794, which destroyed Torre del Greco. Aqueous vapours and hydrochloric gas have also frequently been ob- 
served in the daily ejections of volcanos. It is scarcely possible to conceive the formation of these in the interior of volcanos without the agency of water.

If we admit that water is one of the principal agents in volcanos, we must proceed to examine the real means by which it acts, upon either of the hypotheses we have just laid down concerning the heat of volcanic furnaces. If we suppose, according to the first hypothesis, that the earth continues in a state of incandescence, at a certain depth below its surface, it is impossible to conceive the existence of water at that depth; for the temperature of the earth having formerly been of necessity higher, its fluidity greater, and the thickness of its solid crust less than at the present time, the water must necessarily have disengaged itself from its interior and have risen to the surface.

If we wish therefore to give any air of probability to this hypothesis, and to maintain the importance of water as a principal agent in volcanos, we must assume that it penetrated from the surface downwards to the incandescent strata of the earth; but in order to come to this conclusion, we must suppose that it had a free communication with those strata, that it gradually acquired heat before it reached them, and that the vapour it produced compressed by the weight of its whole liquid column, obtained a sufficient elastic force to elevate the lavas, to produce earthquakes, and to cause all the other terrible phænomena of volcanos.

The difficulties obviously involved in these suppositions, and to which many others might be added, render the hypothesis that the heat of volcanos is to be attributed to the state of incandescence of the earth at a certain depth below the surface perfectly inadmissible. I must further remark that this incandescence is itself quite hypothetical; and that, notwithstanding the observations on the increase of temperature in mines, I regard it as extremely doubtful.

Upon the second hypothesis which we laid down, that the principal cause of volcanic phænomena is a very strong and as yet unneutralized affinity existing between certain substances, and capable of being called into action by fortuitous contact, it is necessary to suppose that the water meets, in the interior of the earth, substances with which it has an affinity so strong as to effect its decomposition and to disengage a considerable quantity of heat.

Now the lavas ejected by volcanos are essentially composed of silica, alumina, lime, soda, and oxide of iron;-bodies which, being all oxiles and incapable of acting upon water, cannot be supposed to have originally existed in their present state in L 2 volcanos. 
volcanos; and from the knowledge which has been obtained of the true nature of these substances, by the admirable discoveries of Sir Humphry Davy, it is probable that the greater part, if not all of them may exist in a metallic state. There is no difficulty in conceiving that by their contact with water they might decompose it, become changed into lava, and produce sufficient heat to account for the greater part of the volcanic phænomena. But as my object is not to construct a system, but, on the contrary, to examine the probability of the two hypotheses under consideration, and to clirect the attention of future observers towards those facts which are most likely to throw light upon the causes of volcanos, I shall proceed to point out the consequences which must result from the adoption of the latter hypothesis. If water be really the agent which sustains the volcanic fires by means of its oxygen, we must admit, as a necessary and very important consequence, that an enormous quantity of hydrogen, either free or combined with some other principle, would be disengaged through the craters of volcanos. Nevertheless it does not appear that the disengagement of hydrogen is very frequent in volcanos. Although, during my residence at Naples in 1805 , with my friends M. Alexander de Humboldt and M. Leopold de Buch, I witnessed frequent explosions of Vesuvius, which threw up melted lava to the height of more than 200 metres, I never perceived any inflammation of hydrogen. Every explosion was followed by columns (tourbillons) of a thick and black smoke, which must have been ignited if they had been composed of hydrogen, being traversed by bodies heated to a temperature higher than was necessary to cause their inflammation.

This smoke, the evident cause of the explosions, contained therefore other fluids than hydrogen. But what was its true nature? If we admit that it is water which furnishes oxygen to volcanos, it will follow that, as its hydrogen does not disengage itself in a free state, it must enter into some combination. It cannot enter into any compound inflammable by means of heat at its contact with the air; it is however very possible that it unites with chlorine to form hydrochloric acid.

A great many observations have in fact been recently given to the world on the presence of this acid in the vapours of Vesuvius; and, according to that excellent observer M. Breislack, it is at least as abundant in them as sulphurous acid. M. Menard de la Groye (whose conclusions on volcanos I however think too precipitate to be adopted), and M. Monticelli to whom the public is indebted for some excellent observations on Vesuvius, also regard the presence of hydrochloric acid in its vapoups as incontestable. I have my- 
self no longer any doubt on this fact, though during my stay in the neighbourhood of Vesuvius I could never distinguish by the smell any thing but sulphurous acid; it is, however, very possible that the extraneous substances mixed with the hydrochloric acid disguised its odour.

It is very much to be wished that M. Monticelli, who is so favourably situated for observing Mount Vesuvius, woukd place some water, containing a little potass, in open vessels on different parts of this rolcano; the water would gradually become charged with acid vapours, and after some time it would be easy to determine their nature.

If the whole of the bydrogen furnished by water to the combustible substances contained in volcanic funaces becomes combined with chlorine, the quantity of hydrochloric acid disengaged by volcanos ought to be enormous. It would then become a matter of surprise that the existence of this acid had not been observed sooner. Besides, the chlorine must enter into combination with the metals of silica, alumina, lime, and oxide of iron; and in order to explain the high temperature of volcanos, we must suppose that the contact of the chlorides of silicium and aluminium with water produces a great evolution of heat. Such a supposition is by no means improbable; but even if we admit it, we are still in want of a great many data, before we can render its application to volcanic phænomena satisfactory.

If the combustible metals are not in the state of chlorides, hydrochlorie acid is then a secondary result; it must procecd from the action of the water upon some chloride (probably that of sodium), an action which is favoured by the mutual affinity of oxides. M. Thenard and I have already shown that if perfectly dry sea-salt and sand are both heated red hot, no hydrochloric acid is evolved: we found also that sea-salt undergoes no alteration from the agency of water alone; but if aqueous vapour is suffered to pass over a nixture of sand or of clay with sea-salt, hydrochloric acid is immediately disengaged in great abundance.

Now the production of this acid by the conjoint action of water and some oxide upon a chloride, must be very fiequent in volcanos. Lava contains chlorides, since it gives them out abundantly when it comes in contact with the air: MM. Monticelli and Covelli extracted, merely by repeated washings with boiling water, more than nine per cent. of sea-salt from the lava of Vesuvius in 1822. It is exhaled through the mouths of volcanos; for very beautiful crystals of it are found in the scoria covering incandescent lava. If, therefore, lava cones in contact with water, cither in the interior of the rol- 
cano, or at the surface of the earth by means of air, hydrochloric acid must necessarily be produced. Messrs. Monticelli and Covelli have in fact observed the production of acid vapours in crevices nearly incandescent; but they took them for sulphurous acid. I am, on the contrary, convinced that they were essentially composed of hydrochloric acid. It is allowable to doubt the accuracy of their observation, since they have expressed considerable uncertainty as to the nature of these acid vapours, whether they were sulphurous or muriatic.

It is well known that lava, especially when it is spongy, contains a great deal of specular iron. In 1805, on inspecting, with M. de Humboldt and M. de Buch, a gallery formed on Vesuvius by the lava of the preceding year, which after encrusting the surface had gradually sunk below it, I saw so great a quantity of specular iron, that it formed what I may be allowed to call a vein : its beautiful micaceous crystals covered the walls of this gallery, in which the temperature was still too high to permit us to stay long. Now the peroxide of iron being in a high degree fixed at a femperature nuch higher than that of lava, it is not probable that it was volatilized in that state: it is very probable that it was primitively in the state of chloride.

If, indeed, we take protochloride of iron which has been melted, and expose it to a dull red heat in a glass tube, and then pass over its surface a current of steam, we shall obtain a great quantity of hydrochloric acid and of hydrogen gas; and black deutoxide of iron will remain in the tube. If, instead of steam, we use dry oxygen, we shall obtain chlorine and peroxide of iron. 'This experiment is easily made by mixing chloride of iron with dry chlorate of potass; at a very moderate temperature chlorine disengages itself in abundance. If we suffer a stream of moist air to pass over the chloride at the tenperature above mentioned, approaching to a red heat, we olstain chlorine, hydrochloric acid, and peroxide of iron. The effects observed with perchloride of iron are the same. If it be exposed to moisture, hydrochloric acid is immediately obtained, or chlorine if it be exposed to oxygen; in either case peroxide of iron is formed.

I can imagine, therefore, that iron in the state of chloride exists in the smoke exhaled by volcanos, or by their lava at its contact with the air, and that by means of heat, of water, and of the oxygen of the air, it is changed into peroxide, which collects, and assumes a crystalline form during precipitation. If we suffer a stream of chlorine at the temperature of about $\$ 00^{\circ}$ to pass over a steel harpsichorl-wire, the wire immediately becomes incandescent, but not nearly so soon as with 
oxygen. The perchloride of iron is very volatile; it crystallizes on cooling into very small light flakes, which instantly fall into deliquescence on exposure to the air. It heats so strongly with water, that I should not be surprised, if, in a large mass, and with a proportional quantity of water, it should become incandescent. I make this observation in order to suggest to my readers, that if silicium and aluminium really existed in the bowels of the earth in the state of chloride, they might produce a much higher temperature upon coming in contact with water, since their affinity for oxygen is much greater than that of iron.

If, as can hardly be doubted, sulphurous acid be really disengaged from volcanos, it is very difficult to form an opinion of its true origin. Whence should it derive the oxygen necessary to its formation, unless it be the result of the decomposition of some sulphates by the action of heat; and of the affinity of their bases for other bodies? This opinion appears to me to be the most probable; for I cannot conceive, from what is known of the properties of sulphur, that it is an agent in volcanic fires.

Klaproth and M. Vauquelin have conjectured that the colour of basalt might be ascribed to carbon; but, to confute this supposition, we need only remark, tlat when a fusible mineral, even if it contain less than ten hundredths of oxide of iron, is heated to a high temperature in a crucible made of clay and pounded charcoal (creuset brasque), a considerable quantity of iron is produced, as Klaproth has shown in the first volume of his Essays. Messrs. Gueniveau and Berthier assert, moreover, that there remains no more than from three to four hundredths of oxide of iron in the scoria of highly heated furnaces. Now, as lava contains a large proportion of iron, and as the basalt which has been analysed contains from fifteen to twenty-five hundredths of the same substance, it is not probable that carbon could exist in the presence of so large a quantity of iron without reducing it *.

Is it not possible that if hydrogen be disengaged from volcanos, metallic iron, the oxides of which have the property of reducing at a high temperature, may be found in lava? It is at least certain that it does not contain iron in the state of peroxide; for lava acts powerfully on a magnetized bar, and the iron it contains appears to be at the precise degree of oxidation which alone is determinable by water; that is to say, in the state of deutoxide. I have already shown, that if hydrogen be mixed with many times its volume of aqueous vapour, it becomes incapable of reducing oxides of iron.

* When these reflections were read before the Academy of Sciences, M.Vauquelin observed that he had found carbon in the ashes ejected by the last eruption of Vesuvius.-Ann. de Chim. tom. xxiii. p. 195.

The 
The necessity which appears to me to exist for the agency of water in volcanic furnaces, the presence of some hundred parts of soda in lava, as also of sea-salt and of several other chlorides, renders it very probable that it is sea-water which most commonly penetrates into them. One objection, however, which I ought not to conceal, presents itself: namely, that it appears necessarily to follow from this supposition, that the streams of lava would escape through the same chamels which had served to convey the water, since they would experience a slighter resistance in them than in those through which they are raised to the surface of the earth. It might also be expected that the elastic fluids formed in volcanic furnaces before the ascent of lava to the surface of the earth, wonld frequently boil up through those same channels to the surface of the sea. I am not aware that such a phænomenon has ever been observed, though it is very probable that the mophetes, so common in volcanic countries, are produced by these elastic fluids.

On the other hand, we may remark that the long intervals between the ermptions and the state of repose in which volcanos remain for a great number of years, seem to demonstrate that their fires become extinguished, or at least considerably deadened; the water would then penetrate gradually by its own pressure into imperceptible fissures to a great depth in the interior of the earth, and woukd accumulate in the vast cavities it contains. The volcanic fires would afterwards gradually revive, and the lava, after having obstructed the channels through which the water penetrated, would rise to its accustomed vent; the diameter of which must continually increase by the fusion of its coats. These are mere conjectures; but the fact is certain, that water does really exist in volcanic furnaces.

It is evident that the science of volcanos is as yet involved in much uncertainty. Although there are strong grounds for the belief that the earth contains substances in a high degree combustible, we are still in want of those precise observations which might enable us to appreciate their agency in volcanic phænomena. For this purpose an accurate knowledge of the nature of the rapours exhaled by different volcanos is requisite; for the cause which keeps them in activity being certainly the same in each, the products common to all might lead to its discovery. All other products will be accidental; that is to say, they will be the result of the action of heat upon the inert bodies in the neighbourhood of the volcanic furnace.

The great number of burning volcanos spread over the surface of the earth, and the still greater number of mineral masses which bear evident marks of their ancient volcanic origin, ought 
to make us regard the ultimate or outermost stratum of the earth as a crust of scorix, bencath which exist a great many furnaces, some of which are extinguished, while others are rekindled. It is well calculated to excite surprise that the earth, which has endured through so many ages, should still preserve an intestine force sufficient to heave up mountains, overturn cities, and agitate its whole mass.

The greater number of mountains, when they arose from the heart of the earth, must have left these vast cavities, which would remain empty unless filled by water. I think, however, that De Luc and many other geologists have reasoned very erroneously on these cavities, which they imagine stretching out into long galleries, by means of which earthquakes are communicated to a distance.

An earthquake, as Dr. Young has very justly observed, is analogous to a vibration of the air. It is a very strong sonorous undulation, excited in the solid mass of the earth by some commotion which communicates itself with the same rapidity with which sound travels. The astonishing considerations in this great and terrible phænomenon are, the immense extent to which it is felt, the ravages it produces, and the potency of the cause to which it must be attributed. But sufficient attention has not been paid to the ease with which all the particles of a solid mass are agitated. The shock produced by the head of a pin at one end of a long beam causes a vibration through all its fibres, and is distinctly transmitted to an attentive ear at the other end. The motion of a carriage on the pavement shakes vast edifices, and communicates itself through considerable masses, as in the deep quarries under Paris. Is it therefore so astonishing that a violent commotion in the bowels of the earth should make it tremble in a radius of many hundreds of leagues? In conformity with the law of the transmission of motion in elastic bodies, the extreme stratum, finding no other strata to which to transmit its motion, makes an effort to detach itself from the agitated mass, in the same manner as in a row of billiard balls, the first of which is struck in the direction of contact, the last alone detaches itself and receives the motion. This is the idea I have formed of the effects of earthquakes on the surface of the globe; and I should explain their great diversity, by also taking into consideration, with M. de Humboldt, the nature of the soil and the solutions of continuity which it may contain.

In a word, earthquakes are only the propagation of a commotion through the mass of the earth, and are so far from depending on subterranean cavities, that their extent would be greater in proportion as the earth was more homogeneous.

Vol. 62. No. 304. Autg. 1823. 